\title{
\begin{tabular}{ll}
\hline The Journal of ERSA \\
\hline
\end{tabular} REGION

\section{Social Progress for Resilient Regions}

\author{
Pim van Ballekom ${ }^{1}$ \\ ${ }^{1}$ European Investment Bank, Luxembourg, Luxembourg \\ Received: 14 February 2018/Accepted: 23 August 2018
}

\begin{abstract}
This paper is the base text for the speech of the then EIB Vice President ${ }^{1}$ Mr. Pim van Ballekom at the ERSA Congress in Groningen, on August 2017. This text represents his and the Bank's views on the topic "Social Progress for Resilient Regions". Although in his speech he deviated from the prepared speech to react on topics raised by the other speakers, this text and its contents remain valid.
\end{abstract}

Ladies and gentlemen,

I am delighted having the opportunity to address you today at the Policy Day of the ERSA Congress in Groningen.

You might be wondering what the EIB is doing here, as we are a bank and therefore not necessarily known to produce science. We do however support not only scientific projects, but also urban and regional development, by means of financing, advisory services and technical assistance. And as much as we would like for the world to be different, not a lot of things can get done without money, so banks like us will still be needed in the future.

It is good to bear in mind that the EIB is public bank, owned by the 28 member states. We are operating on the basis of policies, guidelines and recommendations of the European Union (Council, Commission and Parliament), indeed we are one of the EU institutions. And since cohesion, urban and regional development are topics high on the EU agenda, it is per definition a core activity of the EIB. In fact, achieving a balanced development of the European Union is the oldest operational priority of the EIB.

\section{The challenges for Regions and Cities}

The White Paper on the Future of Europe (European Commission 2017) makes a powerful statement about the current state of the European integration and its uncertain future. Regions and cities have to deal with the continuing consequences of the financial, the economic, and the migration crisis. They have to master the concrete economic, social, demographic and environmental demands of globalisation, technological change and digital transformation at local level. By doing so they make significant contributions to a wide range of EU objectives and priorities, ranging from the promotion of jobs and growth, integration of migrants and support for climate action.

The Paris Climate Agreement (see, for example, European Commission 2015) and the Sustainable Development Goals - to name but two - provide an impetus for regions and cities to move towards sustainable development. Effects on regional development from

\footnotetext{
${ }^{1}$ Mr. van Ballekom's term as Vice President of the EIB ended January 2018.
} 
natural causes are equally important as those of economic and financial causes and can, in the worst case, reinforce each other.

Regional and urban sustainability are critically linked to how communities recover when they are affected by disasters. Investment in capacity to prevent, prepare, manage and reduce climate and other various types of risks, is therefore essential for building resilient regions and cities. Also essential is strengthening the capacities of governments to plan and implement the recovery processes to deliver an effective response. The EIB is eager to support urban investment programmes in various ways.

\section{Linking regional and urban lending to cohesion policy}

A major part of the EIB activities supporting regions and cities falls under the Bank's policy objective of "cohesion". As said, the support of the European Cohesion policy has been at the heart of EIB operations since its foundation in 1958. It remains central to the task of the EIB that the Bank should continue to facilitate the financing of projects in less-developed regions.

The EIB's strong and continued commitment to support cohesion policies is well documented by our past lending. In the last 10 years (2007-2016) more than 200 billion euros of loans have been provided under the cohesion objective. In my opinion this will remain an objective in the foreseeable future. The more so because of budgetary constraints, national and European. In all policy domains you can identify a shift from grants and subsidies to loans and guarantees. In the new financial framework for the years 2020 and beyond, it is my safe guess that this trend will continue. In fact, the current aim of the European Fund for Strategic Investments (EFSI) is to find alternative ways of financing public needs

\section{Framework Loans}

The EIB has continuously helped European regions and cities to finance their integrated regional and urban development strategies through what we call 'framework loans'. This is a flexible instrument, which allows supporting hundreds or even thousands of smaller projects that the Bank would be unable to finance if they were stand-alone projects. Indeed, though we are a "big" bank in terms of our balance sheet, we only have about 3.000 employees. I know that sounds like a lot, but if you serve 28 EU member states and many projects outside the EU, it is quite modest.

Framework loans fill the gap by covering - under one credit line for a region, province or city - smaller projects across a whole spectrum of sectors: Research and development, transport, broadband, regional and urban mobility, water and wastewater treatment, energy efficiency, healthcare, education, cultural heritage among others. On this basis, the EIB agrees with the region or city a set of upfront project criteria. These are the basis for approving projects in a 3-5 year investment period on an ongoing basis. This approach gives regions and cities the flexibility to handle necessary adaptations in their investment programmes if needed.

Regions and cities that benefit from European Structural and Investment Funds (ESIF) use EIB Framework Loans in particular to pre-finance their national co-financing obligations. These dedicated Framework Loans, called Structural Programme Loans, are important enablers for ESIF based investment across the EU.

In order to give you a better understanding of how regions and cities benefit from the framework loan product, let me give you a few practical examples:

- In Greece, the Bank provided several Structural Programme Loans, which cofinanced the European Structural Funds. The loans supported over 120.000 small projects across the country, including schools, archaeological museums, tourism, vocational training, research, environmental programmes and water and waste projects. They also supported small and medium-sized companies, the backbone of the Greek economy. All these being part of the Integrated Territorial Development Plans. 
- In Italy, we are helping to set up a dedicated Framework Loan to support postdisaster reconstruction and rehabilitation investments in 16 Regions, which have been affected by a series of extreme weather events over the last five years. The investments contribute to the sustainable restoration of livelihoods in the affected areas. It is important to mention that reconstruction will respect new urban planning rules and risk prevention measures to ensure resilience against repetitive events.

- Following the floods in Madeira (2010) and the earthquakes in Murcia, Tuscany and Emilia-Romagna, the Bank supported the sustainable and resilient reconstruction of infrastructure, livelihoods and the economy by dedicated comprehensive multi-sector post-disaster Framework Loans.

But although the EIB is a bank, there are other ways in which we are able to assist projects in cohesion regions. Our advisory services, for example, help local authorities prepare projects better, in order to have an increased change of attracting EU and other funding. Especially under the EFSI, the European Fund for Strategic Investments, central pillar of the so-called Juncker Plan, our possibilities in this area have much increased. For more information on this, contact the "EIAH", the European Investment Advisory Hub, at http://eiah.eib.org/.

\section{Financing the Urban Agenda}

The Pact of Amsterdam sets out the key challenges for urban areas in the EU. The pact calls specifically on the EIB to support its implementation through our lending, co-financing and advising activity. Talking to European cities - many of which are also EIB borrowers - about their financing needs leads us to at least 3 broad conclusions.

1. There are many new demands facing cities and most of them - like providing housing to refugees, tackling climate change and enhancing disaster resilience - are typically not revenue generating, thus they depend directly on the national or city budget, or grant funds, for financing.

2. Many cities in Europe are debt-constrained, and need to make more effective use of their debt capacity. Ways to do this include financial instruments or using private sector vehicles to achieve public goals, but this often puts the challenge on the banks and other lenders because of the higher levels of risk.

3. Cities need access to knowledge and information about financing possibilities, but they do not necessarily need new instruments or facilities. What they need is a more concerted way to help them navigate the vast array of existing facilities and instruments and find out which can best support them.

This is where the EU's one stop shop for cities provides value and that is where we are working with the Commission on the financing component. Examples of urban projects that the EIB has financed include the redevelopment of city centres, the creation of smart districts and eco-quartiers and the modernisation of transport and municipal infrastructure in cities across Europe.

\section{Conclusions}

Regions and cities have to cope with numerous challenges, which require an integrated response in the shape of Integrated territorial development. It is short term as well as long term demands. Economic resilience and resilience against natural disasters, as well as against the effects of climate change are two sides of the same coin. Cohesion policy is the EU's main instrument for responding to uneven development across the Union. The EIB has a good track record in this respect and will continue to assist cities and regions alike, wherever possible, in order to fulfil common European goals. Please remember that the European Investment Bank belongs directly to all member states, therefore it is also YOUR bank.

I thank you for your attention. 


\section{References}

European Commission (2015) Energy Union Package. Communication from the commission to the European parliament and the council. The Paris Protocol - A blueprint for tackling global climate change beyond 2020

European Commission (2017) White Paper on the future of Europe. Reflections and scenarios for the EU27 by 2025 